\title{
Effect of Class Content on Practice Time in the Physical Education of Elementary and High School Students
}

\author{
José Luis Chinchilla Minguet, Iván López Fernández
}

\author{
Faculty of Educational Science, University of Málaga, Spain
}

\begin{abstract}
The article focuses on the efficient use of time in providing high quality physical education in schools. We explore the research base identifying effective physical education teaching in schools, in terms of academic learning time and other time-related variables in physical education lessons.

We compare students' activity levels in two types of physical education sessions which differ with regards to lesson content (technical lessons and games lessons), and to the educational level in which the sessions are given (three stages of elementary education and high school education). A total of 112 lessons involving ten class groups and 255 elementary and high school students were observed using the Placheck method (Siedentop \& Tannehill, 2000). T tests were used to compare the academic learning time engagement levels of technical classes with physical education games classes. In the technical lessons, the students were active $45.6 \%$ of the time during the session, while in the games lessons the students were active $53.2 \%$ of the time. This difference is significant ( $p=0.002$ ). These differences were not significant in the sessions taught in the first and second stages of elementary education. We conclude that scope for students to play a lead role in the physical education session is a determining factor in their activity level during the final stage of elementary education and in high school education. It is therefore recommended that physical educators periodically re-examine not only teaching behaviours, class structures and teaching formats, but also the types of activities they include, in order to provide effective teaching and learning environments for their students.
\end{abstract}

Keywords: $\quad$ time management, teaching behaviours, physical education

\section{Introduction}

The field of physical education has found effective ways of evaluating and improving the performance of teachers in the classroom and the gymnasium (Goss, Jubenville, Ferguson \& Bower, 2003). The historical impact of systematic observation methodology in these advances has been clear. It has been found that teachers are able to improve their teaching if their teaching observed, and if they receive regular feedback based on these observations (De Marco, Mancini, Wuest \& Schempp, 1996; Siedentop \& Tannehill, 2000).

Today's effective teacher is defined as one who has the skills needed to minimize unengaged student time and maximize the time given to active and appropriate learning. This means that teachers must be good managers, must present material clearly to students, select developmentally-appropriate content, and create lessons which promote learning and encourage student participation (Rink \& Hall, 2008).

Using these concepts may lead to a more efficient use of physical education class time, without forgetting the differences between teaching in a gymnasium and in a classroom, or time pressure due to distance between teaching sites, organizational difficulties, or facility and equipment issues and class size. Physical educators must create a learning environment with decreased teacher management and wait time, and increased overall academic learning time. By minimizing wait time and student management time, teachers can allocate more time to students' participation in learning activities (Woods \& Erwin, 2008).

Physical education time management is defined as the time spent on organization and transition activities throughout the lesson, and it has been linked to student achievement and learning, as well as to teacher effectiveness. Academic learning time in physical education has been studied extensively as a measure of students' achievement. The more time the students are engaged in activities appro- 
priate to their skill level, the greater the learning (Silverman, 1985; Beckett, 1989; Silverman, Devillier, \& Ramirez, 1991).

Much research in physical education has focused on the concept of engaged activity time or academic learning time as a means of evaluating effective teaching (Godbout, Brunelle, \& Tousignant, 1983; Beauchamp, Darst \& Thompson, 1990; Silverman, Devillier \& Ramirez, 1991; Laker, 1994; Sau-ching Ha, Chan Wan Ka \& Xu, 2002; Emmanouilidou, Derri, Vassiliadou \& Kioumourtzoglou, 2007; Derri, Emmanouilidou, Vassiliadou, Kioumourtzoglou \& Olave, 2008). Time spent on developmentally-appropriate skills practice, in contrast to the time spent on activities irrelevant to learning goals, contributes to fundamental skills concept learning. Results showed that the more effective teachers spent more lesson time on the functional behaviours of concurrent instruction and intervening instruction, whereas the less effective teachers spent more time on non-interactive behaviours (Hastie, 1994). Behets (1997) confirms that effective teaching involves a lot of practice time and limited instruction and management, and that physical education is 'learning by doing'.

There are other studies which draw a direct link between practice time and health. Warburton and Woods (1996) and Waring, Warburton, and Martin (2009) suggest that, in terms of activity, physical education lessons contribute little to long term health, given the recognised importance of physical activity for a healthy heart, and therefore recommend an increase in students' active involvement in physical education activities if we really want to help to promote schoolchildren's health.

Another field of research looks at teacher training in relation to class time management. In addition to identifying the teaching behaviours able to be improved which influence academic learning time (Sauching Ha, Chan Wan Ka \& Xu, 2003; Emmanouilidou et al., 2007), research shows that practice time is closely linked to teacher training with regards to these behaviours. Faucette and Patterson (1990) compared the teaching behaviours of elementary physical education specialists with those of classroom teachers (non-specialists) when teaching physical education classes, and detected higher levels of activity for students in classes taught by specialists. In the search for strategies for improving the educational efficiency of teachers through specific training programmes, research confirms that planning has a positive effect on some trainee teachers' instructional behaviours, as well as class time management (Barret, 2005; Vassiliadou, Derri, Galanis \& Emmanouilidou, 2009).

Conversely, in research where only the teacher's previous experience was taken into account, irrespective of their training, the new teachers demonstrate higher academic learning time values than teachers with more years of experience (Momodu, 1998; Al-Mulla, 2002).

We also found some studies which compare the academic learning time of students from different geographical areas (Momodu, 1998; Sau-ching Ha et al., 2002) or students of different ages (Goldbout, Brunelle \& Tousignant, 1982).

However, we have found few studies which compare the differences in students' activity level in relation to activity content. Warburton \& Woods (1996) compared the activity levels of twenty children aged 7 to 11 in 11 dance lessons, 10 swimming lessons and 15 games lessons. Of the three areas observed, the children engaged in more moderate to vigorous physical activity in the dance lessons and games lessons. In another study, Cardon, Verstraete, De Clercq and De Bourdeaudhuij (2004) compared the activity levels of swimming classes and non-swimming classes, the former being higher, although the research did not specify the type of activities the students carried out during the non-swimming classes, which would be a determining factor when interpreting the results.

Similarly, few studies have compared differences in practice time according to the content of the physical education class. Therefore, the purpose of this study was to compare student practice times in several elementary and high physical education classes with different teaching content. The research was guided by the following questions: Are there significant differences in practice times for students in physical education classes according to the content of the sessions? Does educational level have an influence on the difference in practice times for students in physical education classes according to the content of the sessions? 


\section{Method}

\section{Participants and Setting}

The study population included 10 elementary and high school class groups (123 boys, 132 girls, ages 6.1 to 17.1; mean age 11.35, $\mathrm{SD}=2.65$ ) from three schools in Malaga (Spain) (Table 1) randomly selected from a larger sample of schools, and their four physical educators.

Table 1. Distribution of student participants by educational level

\begin{tabular}{|c|c|c|c|}
\hline Educational level & Students & Average age & SD \\
\hline Stage 1 Elementary School & 49 & 7.13 & 0.83 \\
\hline Stage 2 Elementary School & 52 & 9.25 & 0.71 \\
\hline Stage 3 Elementary School & 51 & 11.38 & 0.74 \\
\hline High School & 103 & 14.50 & 1.37 \\
\hline Total & 255 & 11.35 & 2.65 \\
\hline
\end{tabular}

The average number of students per class was 25.5 students $(\mathrm{SD}=0.71)$.

\section{Procedure}

A total of 112 physical education lessons were observed during the three month study period (Table 2). Two types of classes with different content were developed: technical lessons $(n=60)$ and games lessons $(\mathrm{n}=52)$. In the technical lessons throwing, twisting, jumping, swinging, and speed-based activities were carried out, in addition to individual sports such as swimming, athletics and wrestling. In the games lessons, traditional games, movement games and group games with a ball were played.

Table 2. Number of classes observed by educational level and content of the session

\begin{tabular}{|c|c|c|c|}
\hline Educational level & Technical lessons & Games lessons & Total lessons \\
\hline $\begin{array}{c}\text { Stage 1 } \\
\text { Elementary School }\end{array}$ & 18 & 12 & 30 \\
\hline $\begin{array}{c}\text { Stage 2 } \\
\text { Elementary School }\end{array}$ & 19 & 17 & 36 \\
\hline $\begin{array}{c}\text { Stage 3 } \\
\text { Elementary School }\end{array}$ & 15 & 10 & 25 \\
\hline High School & 8 & 13 & 21 \\
\hline Total & 60 & 52 & 112 \\
\hline
\end{tabular}

In this study, all education classes were specialist-led. Teachers were asked not to alter their teaching behaviour or lesson content. To avoid behaviour changes, the teachers and students were not informed in advance about why the lessons were being observed.

The actual physical education lesson time began when $51 \%$ of the students had reached the teaching site and ended when half of the class had left the site. Although the theoretical time reserved for each physical education session on the timetable was 60 minutes, in fact the length of the session was less, taking into account travel to the location where the physical education class was taking place. In order to quantify this time, the time the students arrived at and departed from the site where the class was taking place was recorded, following the criteria indicated above. 


\section{Measurements}

The group time-sampling technique, or Placheck method (Planned Activity Check), was used to gather data on the students' activity levels during the observed classes (Siedentop \& Tannehill, 2000). It is a technique used to observe group behaviour at different points during a lesson. The Placheck method is a popular research tool for research into student engagement in physical education settings (Faucette \& Patterson, 1990). For 20 seconds of each minute in the observation period, the observer scanned the activity area from left to right and counted the number of physically active students. Those standing still while waiting for an activity to begin or for a turn in the current activity were considered inactive. The Plachecks in which more than half the students were actively involved were selected, and these were translated into practice time. It should be noted that Placheck does not technically measure the number of times a behaviour occurs, but rather the number or proportion of students engaged in a particular behaviour.

Two doctoral students were trained to use the Placheck method. Observer training consisted of approximately four hours observing videotaped lessons with a trainer. The mean percentage of inter-observer agreement calculated according to the method described by Siedentop (1998) was 95\% during the ten classes in which reliability checks were made. The reliability scores ranged from 90.6 to $97.8 \%$.

\section{Data analysis}

All data were analyzed using SPSS (15.0). Descriptive statistics were used to describe the main features of data, while $\mathrm{T}$ tests were used to compare technical classes with physical education games classes in terms of academic learning time engagement levels.

\section{Results}

Of the theoretical 60 minutes' duration of each of the physical education classes analysed, the students were active for an average of 29.5 minutes, i.e. slightly less than half (49.2\%) of the total class time.

Table 3. Distribution of the mean percentage of class time in which the students were active, by educational level

\begin{tabular}{|c|c|c|c|}
\hline Educational level & Technical lessons & Games lessons & Difference \\
\hline Stage 1 Elementary School & 41.2 & 45.4 & -4.2 \\
\hline Stage 2 Elementary School & 47.8 & 45.1 & 2.7 \\
\hline Stage 3 Elementary School & 48.1 & 62.8 & $-14.7^{\star}$ \\
\hline High School & 45.8 & 63.7 & $-17.9^{\star}$ \\
\hline Total & 45.6 & 53.2 & $-7.9^{\star}$ \\
\hline${ }^{\star} \mathrm{p}<0.01$ & & &
\end{tabular}

In the physical education classes whose content was oriented towards learning technical skills and individual sports $(n=60)$, the students were active $45.6 \%$ of the time during the session, while in sessions consisting of games and group sports $(n=52)$ the students were active $53.2 \%$ of the time (Table 3$)$. This is a significant difference $(\mathrm{p}=0.002)$.

If we analyse the results by educational level, we find that the significant differences are at the highest educational levels, while in the lowest levels the differences are not significant, and even in the second stage of elementary school the class time during which the students are active is slightly higher in sessions with a more technical slant (Figure 1). 


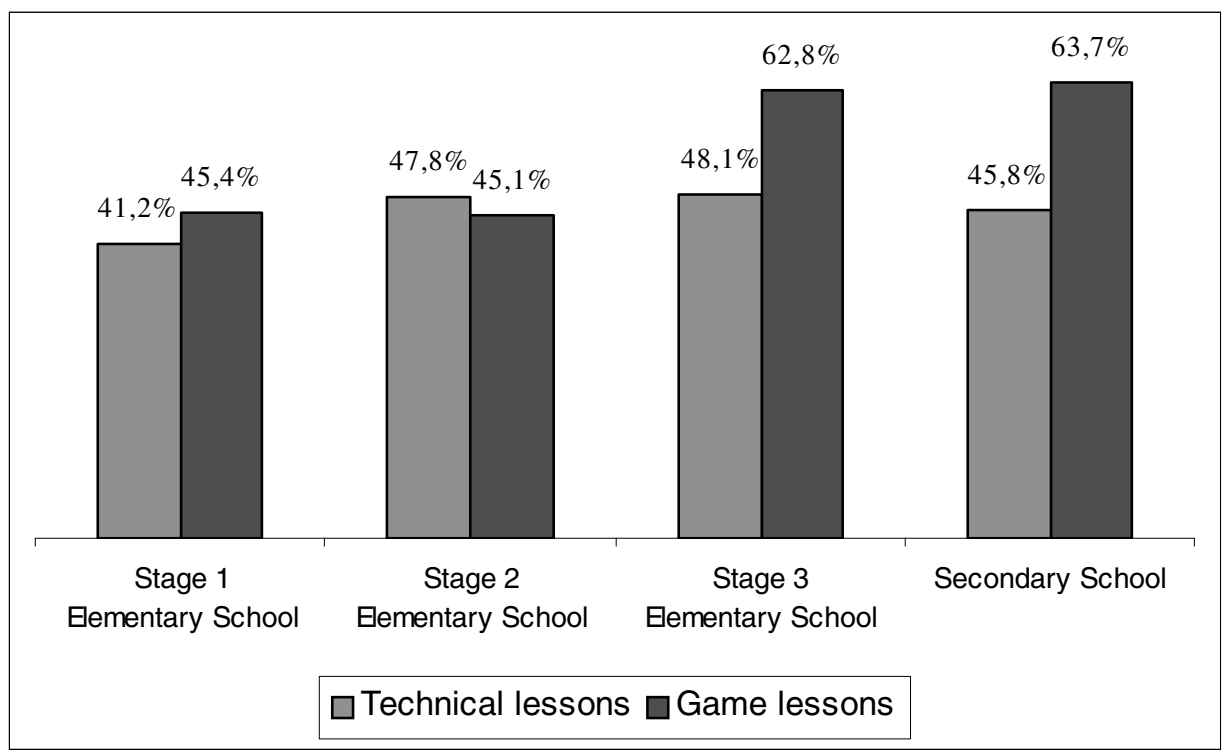

Figure 1. Mean percentage of class time in which the students were active, by session type and educational level

\section{Discussion}

Most research studies find that a small portion of time is actual academic learning time, that students do not participate in motor activities for up to $50 \%$ of the total lesson time and that over $30 \%$ of time is dedicated to administrative and organizational procedures (Golbout et al., 1983; Silverman et al., 1991; Lancaster \& Lacy, 1993; Sau-ching Ha et al., 2003; Tzetzis, Amoutzas \& Kourtessis, 2003; Berry, Miller \& Berry, 2004; Enmanouilidou et al., 2007; Waring et al., 2009). This means that wait time outweighs active learning time in physical education classes. These results confirm those obtained in our study, whereby the percentage of class time in which students were active, in both the technical lessons (45.6\%) and in the games lessons (53.2\%), is close to $50 \%$ in both cases.

The best results obtained in students' activity time in the games lessons are in line with those obtained in the research carried out by Warburton and Woods (1996), in which children were engaged in moderate to vigorous physical activity (MVPA) for $40 \%$ of the time in games lessons and $41 \%$ in dance lessons. Meanwhile, the MVPA involved in swimming lessons (9\%), an individual sport, was much lower. However, Cardon et al. (2004) found that students engaged in more MVPA during swimming classes (52\%) than during non-swimming classes (40\%). The major difference between the results of both studies can be explained if we consider that time spent on transportation and dressing was recorded, but not counted as class time in the second study. Moreover, as we have already mentioned previously, since the type of activities the students carried out during the non-swimming classes was not specified, we cannot draw comparisons in this regard. Comparisons between our study and the results of these two research studies must drawn with caution, since they do not use the same observational tool, but the System for Observing Fitness Instruction Time (SOFIT), to record physical activity engagement levels.

The difference regarding the games lessons can be explained in part if we take into account that the activities in which students participate during this type of session are more open and there is not just one possible valid motor response. In games there is an objective and rules which establish a framework of action, but there are different ways of achieving this objective (Mcneill, Fry, Wright, Tan \& Rossi, 2008). In this sense, as Murcia notes (2003), the student has more freedom and does not have to be governed by rigid motor stereotypes. The inexistence of a such a well-defined training pattern means that the teacher does not require so much information, either in the pre-task explanation or in the feedback following 
it. Furthermore, the majority of activities can be carried out with the students' simultaneous participation. Conversely, in the technical lessons activities are more closed, since there is motor behaviour which has proved more effective for achieving the objective. This means that the student must learn this pattern if they are to achieve the best result in the task. In learning the pattern, the teacher needs to invest more time in the administration of information, and the participation cannot always be simultaneous.

The difference in results according to students' educational level is in tune with the results obtained by Goldbout, Brunelle \& Tousignant (1983) who, examining the amount of academic learning time experienced by elementary and high school students during regular physical education classes, found that academic learning time was higher in high school students. Academic learning time averaged $31.3 \%$ and $36.5 \%$ respectively for the elementary and high school students.

The fact that in the first stages of elementary education the differences in students' activity time are less pronounced can be attributed to the fact that in these first stages the approach is more general, even in the technical tasks, and the educational priority is not to secure a rigid motor result; with the teaching centred more on the process than on the product (Mosston and Ashworth, 1993).

\section{Conclusion}

In light of the study's results, we can conclude that the activity levels of students in physical education classes depends on the content of the session, which in turn is dependent on the student's educational level. In physical education classes in which the technical tasks or those carried out individually require students to take a leading role, the time in which the students are active and involved in the activity is significantly less in comparison with classes in which the main content consists of group games and sports. This difference is more pronounced in the third stage of elementary education and in high school education.

However, in all cases the level of activity of the students in physical education classes is low, at around $50 \%$ of class time. This means that in almost half the class time the students remain inactive even when the content of the session is group games and sports, which lend themselves to simultaneous, less rigid participation. Comprehensive efforts are needed to increase physical activity levels during both types of physical education classes.

This suggests that it may be advisable to continue research in order to improve students' activity levels in physical education classes, since this is linked to the effectiveness of the teaching and, in particular, to the practice of a physical activity which is beneficial for students' health. Moreover, with the continued threat of further reductions in physical education curriculum time, it seems vital to study how physical education lessons can be most effective and provide opportunities for all students to experience appropriate levels of physical activity.

Since the content of physical education teaching has an effect on activity time in physical education classes at particular ages, we suggest new strands of research to analyse the possible influence of teaching methodology on students' activity level, since the teaching strategy used may be, as Barret (2005) indicates, a determining factor.

\section{References}

Al-Mulla A, F. (2002). Comparison of academic learning time in elementary school physical education classes taught by novice and experienced teachers in Bahrain. Journal of the International Council for Health, Physical Education, Recreation, Sport \& Dance, 38(1), 15-19.

Barrett, T. (2005). Effects of Cooperative Learning on Performance of Sixth-Grade Physical Education Students. Journal of Teaching in Physical Education, 24(1), 88.

Beauchamp, L., Darst, P., \& Thompson, L. (1990). Academic Learning Time as an Indication of Quality High School Physical Education. Journal of Physical Education, Recreation and Dance, 61(1), 92-95. 
Beckett, K.D. (1989). The effects of motor appropriate engagement ALT-PE on achievement in a badminton skill during an experimental unit. The Physical Educator, 46(1), 36-40.

Byra, M., \& Coulon, S. (1994). The Effect of Planning on the Instructional Behaviors of Preservice Teachers. Journal of Teaching in Physical Education, 13(2), 123-139.

Berry, D.C.; Miller, M.G. \& Berry, L.M. (2004). Effects of clinical field-experience setting on athletic training students' perceived percentage of time spent on active learning. Journal of Athletic Training, 39(2), 176-184.

Cardon, G., Verstraete, S., De Clercq, D., \& De Bourdeaudhuij, U. (2004). Physical Activity Levels in Elementary-School Physical Education: A Comparison of Swimming and Nonswimming Classes. Journal of Teaching in Physical Education, 23(3), 252-263.

De Marco, G., Mancini, V., Wuest, D., \& Schempp, P. (1996). Becoming reacquainted with a once familiar and still valuable tool: systematic observation methodology revisited. International Journal of Physical Education, 32(1), 17-26.

Derri, V., Emmanouilidou, K., Vassiliadou, O., Kioumourtzoglou, E., \& Olave, E. L. (2008). Academic learning time in physical education (ALT-PE): is it related to fundamental movement skill acquisition and learning?. RICYDE. Revista Internacional de Ciencias del Deporte, 3(6), 12.

Emmanouilidou, K., Derri, V., Vasiliadou, O., \& Kioumourtzoglou, E. (2007). Academic Learning Time in Elementary Physical Education Class. Inquiries in Sport \& Physical Education, 5(1), 1-9.

Faucette, N., \& Patterson, P. (1990). Comparing teaching behaviors and student activity levels in classes taught by P.E. specialists versus nonspecialists. / Comparaison des comportements d'enseignement et des niveaux d'activites des etudiants dans des classes dont les professeurs d'EPS sont soit des specialistes soit des non specialistes. Journal of Teaching in Physical Education, 9(2), 106-114.

Godbout, P., Brunelle, J., \& Tousignant, M. (1983). Academic learning time in elementary and secondary physical education classes. Research Quarterly for Exercise \& Sport, 54(1), 11-19.

Goss, B., Jubenville, C., Ferguson, J., \& Bower, C. (2003). „4 steps to success“: evaluation of coaches of non-revenue producing sports. Sportapolis,

Hastie, P. A. (1994). Selected teacher behaviors and student ALT-PE in secondary school physical education. Journal of Teaching in Physical Education, 13, 242-259.

Laker, A. (1994). A teachers' guide for supervising student teacher. British Journal of Physical Education, 25(4), 31-33.

LaMaster, K. J., \& Lacy, A. C. (1993). Relationship of teacher behaviors to ALT PE in junior high school physical education. Journal of Classroom Interaction, 28(1), 21-25.

Mcneill, M., Fry, J., Wright, S., Tan, C., \& Rossi, T. (2008). Structuring time and questioning to achieve tactical awareness in games lessons. Physical Education \& Sport Pedagogy, 13(3), 231-249.

Momodu, A. (1998). Academic learning time in physical education classes based on teacher qualifications and school locations. Journal of the International Council for Health, Physical Education, Recreation, Sport \& Dance, 34(4), 26-29.

Mosston, M. y Ashworth, S. (1993). La enseñanza de la Educación Física. La reforma de los Estilos de Enseñanza. Barcelona: Hispano Europea.

Murcia, N. (2003). Los condicionantes: concertación e imposición en el desarrollo de la creatividad motriz. Apunts Educación Física y Deportes, 71, 29-39.

Rink, J. E., \& Hall, T. J. (2008). Research on effective teaching in elementary school physical education. The Elementary School Journal, 108(3), 207-218.

Sau-ching Ha, A., Chan Wan Ka, D., \& Xu, B. (2002). Physical education teacher behaviors and student motor appropriate time among Shanghai and Hong Kong schools. Journal of the International Council for Health, Physical Education, Recreation, Sport \& Dance, 38(3), 10-14.

Sau-ching Ha, A., Chan Wan Ka, D., \& Xu, B. (2003). Teacher behaviours and student activity levels in secondary school physical education. Journal of the International Council for Health, Physical Education, Recreation, Sport \& Dance, 39(3), 57-59.

Siedentop, D. (1998). Aprender a enseñar la educación física. Barcelona: Inde. 
Siedentop, D. \& Tannehill, D. (2000). Traditional Methods For Assessing Teaching. In M. Sordi \& S.S. Wright (Eds.), Developing Teaching Skills in Physical Education (pp. 324-328). Mountain View, CA: Mayfield Publishing Company.

Silverman, S. (1985). Relationship of engagement and practice trials to student achievement. Journal of Teaching in Physical Education, (5), 13-21.

Silverman, S., Devillier, R., \& Ramirez, T. (1991). The validity of academic learning time-physical education (ALT-PE) as a process measure of student achievement. Research Quarterly for Exercise and Sport, 62 (3), 319-325.

Tzetzis, G.; Amoutzas, K. \& Kourtessis, T. (2003). A multidimensional analysis of teacher and students interactions and physical activity in physical education classes. Journal of Human Movement Studies, 44(4), 339-251.

Vassiliadou, O., Derri, V., Galanis, N., \& Emmanouilidou, K. (2009). Training in-service physical educators to improve class time management. RICYDE. Revista Internacional de Ciencias del Deporte, 5(17), $33-43$.

Waring, M.; Warburton, P. \& Martin, C. (2007). Observation of children's physical activity levels in primary school: Is the school an ideal setting for meeting government activity targets?. European Physical Education Review, 13(1), 25-40.

Warburton, P., \& Woods, J. (1996). Observation of children's physical activity levels during primary school physical education lessons. European Journal of Physical Education, 1(1), 56-65.

Woods, M., \& Erwin, H. (2008). Using Good B.E.H.A.V.I.O.R. to Improve the Learning Environment. Journal of Physical Education, Recreation \& Dance, 79(4), 14-16. 